\title{
Kebersyukuran, Self-Compassion, dan Kesejahteraan Psikologi pada Caregiver Skizofrenia
}

\section{Endah Puspita Sari, Wardah Roudhotina, Nur Aisyah Rahmani, Mirza Muchammad Iqbal}

\author{
Program Studi Psikologi, Universitas Islam Indonesia \\ email:endah_puspita_sari@uii.ac.id
}

\begin{tabular}{l} 
Artikel INFO \\
\hline Diterima:29 Jan 2020 \\
Direvisi :29 April 2020 \\
Disetujui: 28 Mei 2020 \\
\hline DOI: \\
http://dx.doi.org/10.24014/ \\
jp.v14i2.9081
\end{tabular}

\begin{abstract}
Abstrak
Penelitian-penelitian pendahuluan menemukan bahwa terdapat beban yang harus dihadapi caregiver skizofrenia dalam merawat penderita. Beban-beban tersebut dapat membuat keberfungsian psikologis caregiver menjadi menurun. Keberfungsian psikologi dapat diukur menggunakan kesejahteraan psikologi. Penelitian ini bertujuan untuk mengetahui apakah ada hubungan antara kebersyukuran dan self-compassion terhadap kesejahteraan psikologi pada caregiver skizofrenia. Penelitian ini dilakukan dengan metode kuantitatif menggunakan analisis regresi. Peneliti melakukan metode sampling berupa convenience sampling kepada sejumlah 43 caregiver skizofrenia yang berasal dari salah satu rumah sakit jiwa di Yogyakarta dan salah satu puskesmas di Kabupaten Sleman. Berdasarkan analisis yang dilakukan, dapat disimpulkan bahwa kebersyukuran dan self-compassion secara bersama-sama dapat memprediksi secara signifikan kesejahteraan psikologi pada caregiver skizofrenia $(R=0.467, p=0.007)$. Implikasi untuk penelitian mendatang dan aplikasi akan dijelaskan lebih lanjut dalam tulisan ini.
\end{abstract}

Kata kunci: kesejahteraan psikologi, kebersyukuran, self-compassion, caregiver skizofrenia

\begin{abstract}
Previous studies have found that there were burdens that schizophrenia caregivers must face in treating the patients. Those burdens made the psychological function of caregiver not optimum. The psychological function can be measured by psychological well-being. This study aims to determine gratitude and self-compassion on psychological well-being in schizophrenic caregivers. This study was conducted with quantitative method using regression analysis. Researchers conducted convenience sampling to 43 schizophrenic caregivers who came from one of mental health hospital in Yogyakarta and one of public health center in Sleman Regency. The result of the analysis indicates that gratitude and self-compassion were significantly related to psychological well-being in schizophrenic caregiver $(R=0.467, p=0.007)$. Implications for future research and applications of the construct will be discussed.
\end{abstract}

Keywords: psychological well-being, gratitude, self-compassion, schizophrenia caregiver

\section{Pendahuluan}

Daerah Istimewa Yogyakarta (DIY) merupakan salah satu provinsi yang memiliki prevalensi penderita gangguan jiwa tertinggi di Indonesia. Berdasarkan data Riset Kesehatan Dasar tahun 2013 dan 2018, diketahui bahwa terjadi peningkatan prevalensi penderita skizofrenia di DIY yaitu dari 2,7 per mil penderita skizofrenia menjadi 10 mil penderita skizofrenia. Hal ini menunjukkan bahwa jumlah penderita skizofrenia di DIY, bahkan sejak riskesdas tahun 2013, sudah lebih tinggi dari rata-rata prevalensi skizofrenia di Indonesia yaitu sebesar 1,7 per mil (Departemen Kesehatan 
Republik Indonesia, 2013) (Departemen Kesehatan Republik Indonesia, 2018).

Menurut Rofail, Regnault, le Scouiller, Lambert, dan Zarit (2016), skizofrenia adalah gangguan jiwa berat yang menuntun pada menurunnya keberfungsian sehari-hari penderita. Penderita skizofrenia mengalami penurunan kapasitas kognitif dan keterampilan dalam berhubungan sosial, ketidakmampuan melakukan rawat diri, dan memenuhi kebutuhan melayani diri sendiri (Harvey \& Strassnig, 2012). Gater, Rofail, Marshall, Tolley, Abetz-Webb, Zarit, dan Berardo (2015) menjelaskan bahwa dari waktu ke waktu, terjadi perubahan pelayanan perawatan dari rumah sakit jiwa ke pelayanan rawat jalan, pelayanan komunitas, atau caregiver.

Caregiver didefinisikan sebagai individu yang memiliki tanggung jawab utama untuk mengelola kesejahteraan individu lain yang didiagnosis memiliki penyakit fisik atau gangguan jiwa tertentu dalam kapasitas sebagai individu yang tidak dibayar (Rofail dkk., 2016). Hasil penelitian pendahuluan yang dilakukan peneliti, yang dikuatkan oleh penelitian Berglund, Lytsy, dan Westerling (2015) menemukan bahwa aktivitas caregiving dapat membuat kesejahteraan psikologis caregiver menurun. Khususnya pada konteks caregiver skizofrenia, caregiver harus menghadapi munculnya simtom-simtom yang dialami penderita secara tidak terduga sehingga tidak jarang muncul pengucilan dari masyarakat dan munculnya berbagai emosi dalam diri caregiver (rasa malu, rasa marah, rasa bersalah, rasa berduka, rasa kehilangan) (Ergetie, Yohanes, Asrat, Demeke, Abate, \& Tareke, 2018). Selain itu, caregiver juga kerap kali merasa burn out ketika melakukan aktivitas caregiving dikarenakan fokus utama pada merawat penderita, bukan kepada pemenuhan dan pengembangan kebutuhan diri caregiver dan anggota keluarga yang lain (Wasserman, De Mamani, \& Suro, 2012).

Di Indonesia sendiri, beban caregiver penderita skizofrenia semakin bertambah. Hal ini berdasarkan wawancara peneliti kepada salah seorang perawat di sebuah rumah sakit jiwa bahwa sejak diterapkannya program jaminan kesehatan oleh pemerintah, berlaku ketentuan bahwa setiap pasien skizofrenia yang dirawat inap di rumah sakit jiwa hanya berhak untuk tinggal maksimal selama 20 hari. Setelah lewat dari waktu tersebut maka pasien akan dikembalikan kepada keluarga di rumah. Hal ini membawa dampak bahwa caregiver harus siap merawat penderita, apa pun kondisi penderita. Kondisi penderita yang belum stabil tentu membuat beban caregiver semakin berat. Semakin berat beban caregiver mendorong semakin rendahnya kesejahteraan psikologis caregiver skizofrenia (Mohammed \& Ghaith, 2018).

Rofail dkk. (2016) menjelaskan bahwa beban caregiver penderita gangguan skizofrenia terkait berbagai dimensi kehidupan caregiver (sosial, fisiologis, perilaku, fungsional, mental, medis, dan finansial). Beban yang ditanggung caregiver gangguan jiwa memunculkan stres psikologis, yang berdampak pada kesejahteraan psikologis caregiver (Mohammed \& Ghaith, 2018). Ryff (2018b) menyatakan bahwa penelitian tentang kesejahteraan psikologi menjadi respon terhadap berbagai macam tantangan kehidupan dalam konteks keluarga, misalnya kematian pasangan, kematian anak, dan juga caregiving.

Ryff (2014) menerjemahkan terma eudaimonia sebagai aktivitas-aktivitas kebajikan, yang diuraikan Aristoteles menjadi perjuangan optimal untuk mengaktualisasikan potensi-potensi yang ada di dalam diri. Lebih jauh, Ryff (2014) menawarkan konsep kesejahteraan psikologi atau konsep keberfungsian psikologis yang positif untuk menerjemahkan terma eudaimonia. Konsep kesejahteraan psikologi terdiri dari enam komponen (Ryff, 2018a), yaitu memiliki kapasitas self-regulating, self-determining, dan mandiri (autonomy), memiliki kemampuan untuk mengubah kondisi lingkungan secara kreatif melalui aktivitas fisik dan mental juga mengambil kesempatan yang disediakan lingkungan (environmental mastery), memiliki keterlibatan secara bermakna dengan kehidupan yang dijalani (purpose in life), memiliki keterhubungan dengan individu lain (positive relations), memiliki kesadaran dan upaya untuk merealisasikan potensi diri (personal growth), dan memiliki penerimaan positif atas kelebihan dan kekurangan diri (self-acceptance). 
Peneliti di Indonesia yang mengkaji tentang kesejahteraan psikologi pada caregiver skizofrenia adalah Vania dan Dewi (2014) juga Prasetyo dan Subandi (2014). Pada penelitian Vania dan Dewi (2014), kesejahteraan psikologi caregiver skizofrenia ditinjau dari tipe dukungan sosial. Hasil penelitian tersebut menunjukkan bahwa tipe dukungan jaringan sosial menjadi tipe dukungan yang memiliki pengaruh paling signifikan pada subjek penelitian dibanding tipe dukungan yang lainnya. Adapun penelitian Prasetyo dan Subandi (2014) dilakukan dengan metode eksperimen yang dikembangkan dari nilai-nilai budaya Jawa "Narimo Ing Pandum". Hasil penelitian tersebut menunjukkan bahwa kesejahteraan psikologis subjek penelitian meningkat setelah diberikannya intervensi "Narimo Ing Pandum". Selain itu, penelitian tentang kesejahteraan psikologi pada caregiver skizofrenia juga dilakukan oleh Mohammed dan Ghaith (2018). Penelitian tersebut meninjau kesejahteraan psikologi dari beban yang dialami caregiver dan dukungan sosial yang diterima oleh caregiver. Penelitianpenelitian tersebut menunjukkan bahwa masih jarangnya penelitian tentang topik kesejahteraan psikologi pada subjek caregiver skizofrenia dibandingkan topik kualitas hidup pada subjek caregiver skizofrenia (misalnya Zhang, Subramian, Lee, Abdin, Sagayadevan, Jeyagurunathan dkk., 2018). Pada penelitian ini peneliti akan mengkaji kesejahteraan psikologi dari variabel yang berbeda, yaitu kebersyukuran dan self-compassion. Hal ini didasari dari penelitian pendahuluan yang membuktikan secara empiris ada keterkaitan antara kebersyukuran dan kesejahteraan psikologi (Wood, Joseph, \& Maltby, 2009), juga self-compassion dan kesejahteraan psikologi (Neff, 2011). Implikasi yang peneliti harapkan adalah penelitian ini dapat memverifikasi teori kebersyukuran dan self-compassion terhadap kesejahteraan psikologi pada subjek caregiver skizofrenia.

Wood, Froh, dan Geraghty (2010) mendefinisikan kebersyukuran dari dua hal, yaitu bersyukur sebagai emosi yang terjadi setelah individu mendapat bantuan dari individu lain yang dianggap berharga; dan bersyukur yang muncul dari sumber-sumber seperti penghargaan atas kemampuan yang dimiliki atau dari kondisi alam yang membuat sebuah pekerjaan menjadi berhasil diselesaikan. McCullough, Tsang, dan Emmons (2004), berdasarkan pada hierarki pengalaman afektif Rosenberg mengidentifikasi kebersyukuran sebagai trait, emosi, dan mood. Disposisi kebersyukuran didefinisikan sebagai trait afektif yang stabil yang mampu menurunkan ambang batas pengalaman hidup yang patut disyukuri. Sebagai emosi, kebersyukuran didefinisikan sebagai reaksi psikofisiologikal yang akut, intens, dan segera setelah individu mendapat pertolongan dari individu lain. Sebagai mood yang stabil, kebersyukuran didefinisikan sebagai pengalaman kebersyukuran yang dirasakan oleh kesadaran dalam waktu yang lebih halus, luas, dan lama. Dari hasil penelitian menggunakan alat ukur Psychological Well-being Scale 18-item dan Gratitude Questionnaire-6, Wood dkk. (2009) mendapatkan hasil bahwa kebersyukuran adalah indikator penting dari kesejahteraan psikologi. Salah satu penjelasan yang disampaikan oleh Emmons dan Mishra (2011) tentang keterkaitan kebersyukuran dan kesejahteraan psikologiadalah kebersyukuran memfasilitasi individu untuk melakukan coping terhadap situasi yang menimbulkan tekanan, misalnya dengan melakukan positive reframing. Dalam konteks caregiver skizofrenia, caregiver yang bersyukur adalah caregiver yang dapat mengenali, juga mengambil hikmah bahwa dirinya masih diberi kesehatan fisik dan ruhani sehingga masih dapat bermanfaat untuk menolong penderita. Akibatnya, caregiver dapat menikmati waktu untuk merawat penderita dan dapat terus mengatur dirinya untuk berespon secara tepat kepada penderita dan lingkungan sekitar .

Neff (2011) mendefinisikan selfcompassion sebagai memperlakukan diri sendiri dengan kebaikan, mengakui bahwa kekurangan adalah hal yang manusiawi dialami semua manusia, dan tidak mengabaikan juga tidak melebih-lebihkan pemikiran tentang salah satu aspek dalam diri yang tidak disukai. Neff dan Knox (2017) lebih lanjut menjelaskan bahwa self-compassion adalah sumber penting kebahagiaan eudaimonia. Hal ini karena dengan memiliki 
self-compassion, ketika mengalami kondisi yang sulit maka individu akan menghadapinya dengan menyayangi diri sendiri dan mencari makna daripada menghindari rasa sakit yang dialami. Selain itu, self-compassion juga menjadi kekuatan di dalam diri untuk menemukan potensi yang selama ini belum disadari. Hasil penelitian Neff dan Pommier (2013) menemukan bahwa meningkatnya kemampuan menyayangi diri sendiri (selfcompassion) akan mendorong semakin meningkatnya kepedulian kepada individu lain. Hal ini menunjukkan peran penting self-compassion dalam konteks caregiver skizofrenia bahwa kemampuan menyayangi diri sendiri pada caregiver akan mendorong caregiver untuk menyayangi penderita. Hal tersebut dikarenakan caregiver mampu memaafkan situasi-situasi sulit yang muncul akibat kambuhnya gangguan penderita dengan melihat dari sudut pandang penderita dan mengambil hikmah atas kejadian sulit tersebut.

Berdasarkan uraian yang telah peneliti paparkan, peneliti tertarik untuk meneliti keterkaitan kebersyukuran dan selfcompassion terhadap kesejahteraan psikologi pada caregiver skizofrenia. Tujuan dari penelitian ini adalah untuk melihat keterkaitan kebersyukuran dan self-compassion secara bersama-sama terhadap kesejahteraan psikologi caregiver skizofrenia.

\section{Metode}

Subjek

Subjek dalam penelitian ini adalah primary caregiver dari penderita skizofrenia. Individu yang menjadi primary caregiver umumnya adalah anggota keluarga atau kerabat (Berglund dkk., 2015); (Sullivan \& Miller, 2015). Karakteristik dari subjek penelitian ini adalah sudah menjadi primary caregiver penderita skizofrenia minimal satu tahun, dan tinggal satu rumah dengan penderita. Adapun proses rekrutmen subjek dilakukan dengan convenience sampling. Convenience sampling adalah desain sampling yang dilakukan secara tidak acak (Knight, Roosa, \& Umana-Taylor, 2009). Ditambahkan oleh Elfil \& Negida (2017) bahwa teknik convenience sampling merupakan salah satu teknik sampling yang dapat diterapkan pada penelitian klinis karena pertimbangan aksesibilitas dengan subjek penelitian. Protokol penelitian ini telah mendapatkan pengesahan layak etik dari Komite Etik Penelitian Kedokteran dan Kesehatan, Fakultas Kedokteran Universitas Islam Indonesia. Informed consent didapatkan dari seluruh caregiver yang menjadi responden dalam penelitian ini.

Berdasarkan analisis deskriptif data subjek penelitian, diketahui bahwa subjek termuda pada penelitian ini berusia 16 tahun sejumlah 1 orang $(2.3 \%)$, dan subjek tertua berusia 71 tahun sejumlah 1 orang (2.3\%). Sejumlah 30 subjek (69.8\%) masih aktif bekerja selain menjadi caregiver skizofrenia. Selain itu, deskripsi berdasarkan lama merawat menunjukkan bahwa 1 orang telah merawat selama 1 tahun (2.3\%), dan 2 orang subjek sudah merawat selama 30 tahun terakhir $(4.7 \%)$.

\section{Pengukuran}

Penelitian ini dilakukan dengan desain penelitian kuantitatif. Peneliti menggunakan skala sebagai metode pengumpulan data. Instrumen penelitian yang digunakan dalam penelitian ini adalah tiga skala, yaitu skala kesejahteraan psikologi (short version) dari Clarke, Marshall, Ryff, dan Wheaton, (2001), skala self-compassion (short form) dari Neff (2003), dan skala kebersyukuran dari McCullough, Emmons, \& Tsang (2002). Ketiga skala diterjemahkan dari bahasa Inggris ke dalam bahasa Indonesia oleh peneliti dan rekan peneliti yang memiliki latar belakang pendidikan bahasa Inggris. Setelah proses penerjemahan selesai dilakukan, peneliti melakukan uji coba hasil terjemahan kepada dua orang caregiver pasien kanker.

Skala Gratitude Questionnaire 6 Item (GQ-6) terdiri dari enam aitem (McCullough dkk., 2002). Skala GQ-6 merupakan instrumen pengukuran yang diturunkan dari teori kebersyukuran McCullough dkk. (2002). Skala GQ-6 mengukur disposisi kebersyukuran, yaitu mengukur kecenderungan untuk mengenali dan merespon secara emosi melalui rasa terima kasih setelah menerima pertolongan 
dari individu lain (Emmons \& McCullough, 2003). Lebih jauh McCullough dkk. (2002) menjelaskan bahwa skala GQ-6 mengungkap kebersyukuran secara unidimensional. Skala GQ-6 menggunakan model skala Likert dengan tujuh alternatif jawaban. Skor pada aitem favorable bergerak dari angka 7 (sangat sesuai) ke angka 1 (sangat tidak sesuai). Sebaliknya, skor pada aitem unfavorable bergerak dari angka 7 (sangat tidak sesuai) ke angka 1 (sangat sesuai). Salah satu aitem dari skala GQ-6 adalah I have so much in life to be thankful for/banyak hal dalam hidup saya yang harus saya syukuri. Pemilihan alat ukur kerbersyukuran dari McCullough dkk. (2002) berdasarkan penelitian pendahuluan yang sudah dilakukan oleh pembuat alat ukur bahwa cronbach alpha dari inter-item consistency menunjukkan kisaran 0,76 sampai 0,84 .

Skala Self Compassion Scale Short Form (Neff, 2003) menggunakan model skala Likert. Skala ini memiliki lima alternatif jawaban. Skor pada aitem favorable bergerak dari angka 5 (selalu) ke angka 1 (tidak pernah). Sebaliknya, skor pada aitem unfavorable bergerak dari angka 5 (tidak pernah) ke angka 1 (selalu). Salah satu bunyi aitem dari SCS Short Form adalah I am tolerant of my own flaws and inadequacies/saya mencoba untuk memahami dan menerima kepribadian saya yang tidak saya sukai. Pemilihan alat ukur SCS Short Form dari Neff (2003) berdasarkan penelitian pendahuluan yang sudah dilakukan oleh pembuat alat ukur bahwa cronbach alpha dari inter-item consistency menunjukkan kisaran 0,48 sampai 0,91 .

Skala Psychological Well-being Short Version (Clarke dkk., 2001) menggunakan model skala Likert. Skala ini memiliki enam alternatif jawaban. Skor pada aitem favorable bergerak dari angka 6 (sangat sesuai) ke

Tabel 1.Hasil uji normalitas angka 1 (sangat tidak sesuai). Sebaliknya, skor pada aitem unfavorable bergerak dari angka 6 (sangat tidak sesuai) ke angka 1 (sangat sesuai). Salah satu aitem pernyataan dari PWB Short Version adalah The demands of everyday life often get my down/tuntutantuntutan dalam kehidupan sehari-hari sering membuat saya tertekan. Pemilihan alat ukur PWB Short Version dari Clarke dkk. (2001) berdasarkan penelitian pendahuluan yang sudah dilakukan oleh pembuat alat ukur bahwa Cronbach Alpha dari inter-item consistency menunjukkan kisaran 0,33 sampai 0,56.

\section{Analisis Data}

Penelitian ini menggunakan analisis regresi dalam analisis data karena penelitian ini tidak sekedar menguji hubungan antar variabel saja, namun juga ingin melihat kekuatan prediksi dari variabel-variabel bebas terhadap variabel tergantung. Analisis data menggunakan bantuan program SPSS 23.0 for windows.

\section{Hasil}

Pertama, penelitimelakukanujinormalitas. Uji normalitas digunakan untuk mengetahui apakah sebaran data variabel bebas dan variabel tergantung terdistribusi normal atau tidak. Peneliti melakukan uji normalitas menggunakan One Sample KolmogorovSmirnov Test. Apabila hasil menunjukkan bahwa $p>0.05$ artinya data terdistribusi normal. Berdasarkan hasil pengolahan data pada variabel kebersyukuran, diperoleh koefisien $p=0.255(p>0.05)$. Untuk variabel self-compassion diperoleh koefisien $p=0.218$ $(p>0.05)$. Sedangkan variabel kesejahteraan psikologi diperoleh koefisien $p=0.379$ ( $p$ $>0.05)$. Artinya ketiga variabel memenuhi distribusi normal. Hasil uji normalitas terangkum pada tabel 1.

\begin{tabular}{lcc}
\hline \multicolumn{1}{c}{ Variabel } & $\mathbf{p ~ ( > 0 . 0 5 )}$ & Keterangan \\
\hline Kebersyukuran & 0.255 & Normal \\
Self-compassion & 0.218 & Normal \\
Kesejahteraan psikologi & 0.379 & Normal \\
\hline
\end{tabular}

Selanjutnya peneliti melakukan uji linieritas. Uji linieritas digunakan untuk mengetahui apakah variabel bebas dan variabel tergantung memiliki hubungan yang linier. Apabila hasil menunjukkan bahwa $p$ $<0.05$ artinya kedua variabel membentuk 
garis lurus. Berdasarkan hasil uji liniearitas kesejahteraan psikologi dan kebersyukuran menunjukkan koefisien $F=7.318$ dan $p$ $=0.012(p<0.05)$, artinya kesejahteraan psikologi dan kebersyukuran memenuhi asumsi linieritas. Adapun hasil uji linieritas

Tabel 2.Hasil uji linieritas kesejahteraan psikologi dan self-compassion menunjukkan koefisien $=9.858$ dan $p=0.004$ $(p<0.05)$ artinya kesejahteraan psikologi dan self-compassion memenuhi asumsi linieritas. Hasil uji linieritas terangkum pada tabel 2.

\begin{tabular}{lccc}
\hline Variabel & $\mathbf{F}$ & $\mathbf{p ~ ( < 0 . 0 5 )}$ & Keterangan \\
\hline Kesejahteraan psikologi*kebersyukuran & 7.318 & 0.012 & Linier \\
Kesejahteraan psikologi* ${ }^{*}$ self-compassion & 9.858 & 0.004 & Linier \\
\hline
\end{tabular}

Kemudian peneliti melakukan uji multikolinieritas. Hasil uji multikolinearitas dalam penelitian ini diperoleh nilai tolerance sebesar 0.92 dan nilai VIF sebesar 1.087 untuk variabel kebersyukuran, nilai tolerance sebesar 0.92 dan nilai VIF sebesar 1.087 untuk variabel self-compassion. Berdasarkan hasil analisis yang diperoleh dapat dikatakan bahwa pada model regresi penelitian ini tidak terjadi gejala multikolinearitas.

Terakhir peneliti melakukan uji asumsi. Berdasarkan analisis regresi metode enter yang dilakukan, diketahuibahwaadahubungan yang signifikan antara kebersyukuran, selfcompassion dan kesejahteraan psikologi pada caregiver skizofrenia. Hasil tersebut diperoleh dari nilai $\mathrm{R}=0.467$ dan nilai $\mathrm{p}=$ 0.007 ( $p<0.01)$. Dengan demikian, dapat dikatakan bahwa kebersyukuran dan selfcompassion secara bersama-sama dapat memprediksi secara signifikan kesejahteraan psikologi pada caregiver skizofrenia, dengan sumbangan efektif sebesar 21.8 persen. Adapun berdasarkan analisis regresi metode stepwise yang dilakukan, diketahui bahwa self-compassion memberikan sumbangan sebesar 17 persen, dan kebersyukuran memberikan sumbangan sebesar 4.8 persen.

\section{Pembahasan}

Hasil penelitian ini membuktikan bahwa kebersyukuran dan self-compassion sangat erat berkaitan dengan keenam dimensi kesejahteraan psikologi. Hasil penelitian ini mendukung hasil penelitian Voci, Veneziani, dan Fuochi (2018) bahwa variabel kebersyukuran dan self-compassion memiliki kaitan yang penting dengan kesejahteraan psikologi. Dinamika yang dijabarkan dalam penelitian tersebut adalah bahwa individu yang bersyukur mampu membangun hubungan yang hangat dengan individu lain. Individu yang bersyukur juga mampu mengambil hikmah dari pengalaman yang sudah dilaluinya dan saat ini sedang dihadapnya. Individu yang memiliki selfcompassion memperlakukan dirinya dengan penuh penerimaan dan penghargaan, bukan kritikan. Merujuk pada penjelasan tersebut maka penting bagi caregiver skizofrenia untuk bersyukur dan memiliki kemampuan menyayangi dirinya sendiri agar tercapai kesejahteraan psikologi. Adapun perbedaan penelitian ini dengan penelitian Voci dkk., (2018) adalah pada subjek penelitian, yaitu penelitian tersebut menggunakan masyarakat Italia secara umum.

Emmons dan Mishra (2011) di dalam bukunya membuat beberapa hipotesis yang membuktikan keterkaitan kebersyukuran dengan kesejahteraan psikologi. Sesuai konteks penelitian ini, peneliti merujuk pada tiga hipotesis yang diajukan Emmons \& Mishra (2011). Pertama, kebersyukuran memfasilitasi coping terhadap peristiwa hidup yang menekan, yang dikuatkan oleh penelitian pendahuluan oleh Wood, Joseph, dan Linley (2007) bahwa individu yang bersyukur akan melakukan gaya coping berupa mencari dukungan sosial, positive reframing, approach-oriented problem solving, dan active coping. Kedua, kebersyukuran membangun dan mempertahankan jaringan sosial. Seperti dijelaskan oleh Algoe, Haidt, dan Gable (2008) bahwa kebersyukuran berfungsi sebagai pendorong terbentuknya dan bertahannya hubungan sosial. Ketiga, kebersyukuran 
memotivasi dilakukannya perilaku moral. Hal ini karena individu yang bersyukur merasa sudah mendapatkan pertolongan dari individu lain, sehingga mendorong dirinya untuk melakukan kebaikan kepada individu lain juga (Emmons \& Mishra, 2011). Selain itu, Wood dkk. (2009) merujuk pada berbagai penelitian pendahuluan, menyimpulkan bahwa individu yang bersyukur mampu menghindari kebosanan hidup sehari-hari dengan mengapresiasi peristiwa-peristiwa kecil yang datang.

Caregiver sudah mendedikasikan waktu dan tenaganya untuk melalukan aktivitas caregiving sehingga caregiver harus belajar untuk mempedulikan diri sendiri; secara fisik maupun psikologis (Sullivan \& Miller, 2015). Dalam penelitian pada subjek ibu yang memiliki anak penderita spektrum autis, dijelaskan oleh Faso, Neal-Beevers, dan Carlson (2013) bahwa ketika caregiver merasa putus asa dan meningkat rasa khawatir akan masa depan, subjek penelitian yang memiliki self-compassion dapat melawan pemikiran-pemikiran negatif tersebut. Hal tersebut senada dengan hasil penelitian Raes (2010) tentang keterkaitan self-compassion dan kesejahteraan psikologi bahwa selfcompassion menjadi faktor protektif untuk memunculkan resiliensi emosi pada individu terhadap peristiwa negatif.

Berdasarkan kategorisasi variabel penelitian, terlihat bahwa dari ketiga variabel yang diteliti, semua subjek berada pada kategori sedang dan tinggi. Wawancara yang peneliti lakukan setelah pengisian data didapatkan bahwa para subjek penelitian rajin mengikuti family gathering yang diadakan oleh psikolog dan tenaga kesehatan yang bertugas di lokasi penelitian. Para tenaga kesehatan di lokasi penelitian secara berkala mengundang caregiver skizofrenia untuk diberikan psikoedukasi tentang skizofrenia. Dalam kegiatan tersebut, para subjek mengakui mendapat tambahan ilmu, selain menambah teman. Hal penting lain yang didapatkan oleh para subjek penelitian dengan mengikuti family gathering adalah menyadari bahwa dirinya tidak sendiri dalam menghadapi beban merawat penderita skizofrenia. Hal ini sejalan dengan hasil penelitian Lee, Yang, Chen, Hung, Lin, Chang, dan Cheng (2006) bahwa dukungan sosial memiliki buffer effect pada caregiver skizofrenia.

Hal menarik lain yang ditemukan dalam penelitian ini adalah status bekerja dari para subjek penelitian. Subjek yang bekerja dalam penelitian ini sejumlah 30 orang. Dari hasil penelitian Bourke-Taylor, Howie, dan Law (Vasilopoulou \& Nisbet, 2016) ditemukan bahwa ibu bekerja yang menjadi caregiver bagi anak penderita Autis Spectrum Disorder memiliki kesehatan mental yang lebih positif dibanding ibu yang tidak bekerja yang menjadi caregiver bagi anak penderita ASD. Penelitian menunjukkan bahwa kesehatan mental tersebut terjadi karena adanya pendapatan yang diperoleh dalam keluarga menjadi lebih tinggi (McKee-Ryan, Song, Wanberg, \& Kinicki, 2002 dalam (Vasilopoulou \& Nisbet, 2016). Adapun menurut peneliti, status bekerja juga terkait dengan coping. Hal ini karena caregiver yang bekerja memiliki kesempatan untuk tidak melulu menghabiskan waktu melakukan kegiatan caregiving. Subjek bisa sejenak bertemu dengan orang lain dan hal baru yang dapat mengalihkan kebosanan dan beban yang dirasakan selama merawat penderita skizofrenia. Hal inilah yang membuat data subjek penelitian pada ketiga variabel berada pada kategori sedang dan tinggi. Penelitian Wood dkk. (2007) menguatkan bahwa coping merupakan salah satu sumber daya psikologis bagi individu-individu yang memiliki kebersyukuran.

Keterbatasan penelitian ini adalah pertama, terbatasnya jumlah subjek penelitian. Subjek penelitian ini belum dapat merepresentasikan hasil RISKESDAS 2018 yang menyatakan bahwa penderita skizofrenia di Provinsi Daerah Istimewa Yogyakarta termasuk kategori yang tertinggi di Indonesia. Peneliti selanjutnya dapat memilih lokasi penelitian yang lebih luas untuk menjangkau lebih banyak lagi subjek penelitian. Kedua, instrumen pengukuran yang belum mengikuti kaidah adaptasi alat ukur (Borsa, Damásio, \& Bandeira, 2012). Peneliti selanjutnya diharapkan lebih mengikuti prosedur adaptasi dan validasi lintas budaya dalam menggunakan instrumen pengukuran psikologi. Ketiga, reliabilitas skala kesejahteraan psikologi yang rendah. Clarke dkk. (2001) menjelaskan bahwa masih 
ada beberapa kelemahan terkait dengan reliabilitas pada alat ukur Psychological WellBeing Short Version.

\section{Kesimpulan}

Penelitian ini menyediakan bukti empiris bahwa kesejahteraan psikologi adalah isu yang terkait erat dengan caregiver skizofrenia. Penelitian ini mendukung perlunya mengkaji lebih jauh bahwa caregiver skizofrenia penting memiliki kebersyukuran dan mencintai diri sendiri untuk memunculkan perasaan sejahtera secara psikologi dalam dirinya. Saran untuk peneliti selanjutnya adalah: pertama, menambah jumlah subjek penelitian agar dapat merepresentasikan populasi. Kedua, mempertimbangkan menggunakan alat ukur kesejahteraan psikologi yang berbeda. Ketiga, proses adaptasi alat ukur dilakukan sesuai prosedur. Terakhir, peneliti selanjutnya dapat menindaklanjuti penelitian ini dengan melakukan penelitian eksperimen berupa pelatihan kebersyukuran dan pelatihan self-compassion kepada caregiver skizofrenia agar dapat mencapai kesejahteraan psikologi.

\section{Acknowledgement}

Peneliti mengucapkan terima kasih kepada Direktorat Penelitian dan Pengabdian Masyarakat Universitas Islam Indonesia karena telah mendanai penelitian ini (nomor hibah 004/Dir/DPPM/70/Pen.Pemula/PII/VIII/ 2016).

\section{Daftar Pustaka}

Algoe, S. B., Haidt, J., \& Gable, S. L. (2008). Beyond reciprocity: Gratitude and relationships in everyday life. Emotion, 8(3), 425-429. https://doi. org/10.1037/1528-3542.8.3.425.

Berglund, E., Lytsy, P., \& Westerling, R. (2015). Health and wellbeing in informal caregivers and non-caregivers: A comparative cross-sectional study of the Swedish a general population. Health and Quality of Life Outcomes, 13(109), 1-11.https://doi.org/10.1186/s12955015-0309-2
Borsa, J. C., Damásio, B. F., \& Bandeira, D. R. (2012). Cross-cultural adaptation and validation of psychological instruments: Some considerations. Paideia, 22(53), 423-432. https://doi.org/10.1590/198243272253201314

Clarke, P. J., Marshall, V. W., Ryff, C. D., \& Wheaton, B. (2001). Measuring psychological well-being in the Canadian study of health and aging. International Psychogeriatrics, 13(1), 79-90. https:// doi.org/10.1017/S1041610202008013

Elfil, M., \& Negida, A. (2017). Sampling methods in Clinical Research; an Educational Review. Emergency, 5(1), e52. https://doi.org/10.22037/ emergency.v5i1.15215

Emmons, R. A., \& McCullough, M. E. (2003). Counting blessings versus burdens: An experimental investigation of gratitude and subjective well-being in daily life. Journal of Personality and Social Psychology., 84(2), 377-389.

Emmons, R. A., \& Mishra, A. (2011). Why gratitude enhances well-being: What we know, what we need to know. In K. M. Sheldon, T. B. Kashdan, \& M. E. Steger (Eds.), Designing positive psychology: Taking stock and moving forward (pp. 248-262). https://doi.org/10.1093/acprof :oso/9780195373585.003.0016

Ergetie, T., Yohanes, Z., Asrat, B., Demeke, W., Abate, A., \& Tareke, M. (2018). Perceived stigma among non-professional caregivers of people with severe mental illness, Bahir Dar, northwest Ethiopia. Annals of General Psychiatry, 17(42), 1-8. https:// doi.org/10.1186/s12991-018-0212-4

Faso, D. J., Neal-Beevers, A. R., \& Carlson, C. L. (2013). Vicarious futurity, hope, and well-being in parents of children with autism spectrum disorder. Research in Autism Spectrum Disorders, 7(2), 288297. https://doi.org/10.1016/j.rasd.2012. 08.014

Gater, A., Rofail, D., Marshall, C., Tolley, C., Abetz-Webb, L., Zarit, S. H., \& Berardo, C. G. (2015). Assessing the impact of caring for a person with schizophrenia: Development of the Schizophrenia Caregiver Questionnaire. Patient, 8(6), 507-520. https://doi.org/10.1007/ 
s40271-015-0114-3

Harvey, P. D., \& Strassnig, M. (2012). Predicting the severity of everyday functional disability in people with schizophrenia: Cognitive deficits, functional capacity, symptoms, and health status. World Psychiatry, 11(2), 73-79. https://doi. org/10.1016/j.wpsyc.2012.05.004

Indonesia, D. K. R. (2013). Riset Kesehatan Dasar. Retrieved from http://www. depkes.go.id/resources/download/ general/Hasil Riskesdas 2013.pdf.\%0A

Kesehatan Republik Indonesia, D. (2018). Hasil Utama Riskesdas 2018. In Badan Penelitian dan Pengembangan Kesehatan Kementerian Kesehatan Republik Indonesia. https://doi.org/1 Desember 2013

Knight, G. P., Roosa, M. W., \& Umana-Taylor, A. J. (2009). Sampling, recruiting, and retaining diverse samples. In G. P. Knight, M. W. Roosa, \& A. J. Umana-Taylor (Eds.), Studying ethnic minority and economically disadvantage populations: Methodological challenges and best practices (pp. 29-78). Washington DC: American Psychological Association.

Lee, T. C., Yang, Y. K., Chen, P. S., Hung, N. C., Lin, S. H., Chang, F. L., \& Cheng, S. H. (2006). Different dimensions of social support for the caregivers of patients with schizophrenia: Main effect and stress-buffering models. Psychiatry and Clinical Neurosciences, 60(5), 546-550. https://doi.org/10.1111/j.14401819.2006.01556.x

McCullough, M. E., Emmons, R. A., \& Tsang, J. (2002). The grateful disposition: A conceptual and empirical topography. Journal of Personality and Social Psychology, 82(1), 112-127.

McCullough, M. E., Tsang, J., \& Emmons, R. A. (2004). Gratitude in Intermediate affective terrain: Links of grateful moods to individual differences and daily emotional experience. Journal of Personality and Social Psychology, 86(2), 295-309. https://doi.org/10.1037/00223514.86.2.295

Mohammed, S. F. M., \& Ghaith, R. F. A. H. (2018). Relationship between burden, psychological well-being, and social support among caregivers of mentally ill patients. Egyptian Nursing Journal, 15, 268-280. https://doi.org/10.4103/ENJ. ENJ_17_18

Neff, K. D. (2003). Development and validation of a scale to measure self-compassion. Self and Identity, 2, 223-250.

Neff, K. D. (2011). Self-compassion, selfesteem, and well-being. Social and Personality Psychology Compass, 5(1), 1-12.https://doi.org/10.1111/j.17519004.2010.00330.x

Neff, K. D., \& Knox, M. C. (2017). Selfcompassion. In V. Zeigler-Hill \& T. K. Shackelford (Eds.), Encyclopedia of personality and individual differences. https://doi.org/10.1007/978-3-31928099-8

Neff, K. D., \& Pommier, E. (2013). The relationship between self-compassion and other-focused concern among college undergraduates, community adults, and practicing meditators. Self and Identity, 12(2), 1-17. https://doi.org /10.1080/15298868.2011.649546

Prasetyo, N. H., \& Subandi. (2014). Program intervensi Narimo Ing Pandum untuk meningkatkan kesejahteraan psikologis keluarga pasien skizofrenia. Jurnal Intervensi Psikologi, 6(2), 151-170.

Raes, F. (2010). Rumination and worry as mediators of the relationship between self-compassion and depression and anxiety. Personality and Individual Differences, 48(6), 757-761. https://doi. org/10.1016/j.paid.2010.01.023

Rofail, D., Regnault,A., leScouiller, S., Lambert, J., \& Zarit, S. H. (2016). Assessing the impact on caregivers of patients with schizophrenia: Psychometric validation of the Schizophrenia Caregiver Questionnaire (SCQ). BMC Psychiatry, 16(245). https://doi.org/10.1186/s12888016-0951-1

Ryff, C. D. (2014). Psychological well-being revisited: Advances in the science and practice of eudaimonia. Psychotherapy and Psychosomatics, 83, 10-28. https:// doi.org/10.1159/000353263

Ryff, C. D. (2018a). Eudaimonic well-being: Highlights from 25 years of inquiry. In K. Shigemasu, S. Kuwano, T. Sato, \& T. 
Matsuzawa (Eds.), Diversity in Harmony - Insights from Psychology: Proceedings of the 31st International Congress of Psychology (First edit, pp. 375-395). New York: John Wiley \& Sons, Ltd.

Ryff, C. D. (2018b). Well-being with soul: Science in pursuit of human potential. Perspectives on Psychological Science, 13(2), 242-248. https://doi.org/10.1177/ 1745691617699836

Sullivan, A. B., \& Miller, D. (2015). Who is taking care of the caregiver? Journal of Patient Experience, 2(1), 7-12. https:// doi.org/10.1177/237437431500200103

Vania, I. W., \& Dewi, K. S. (2014). Hubungan antara dukungan sosial dengan psychological well-being caregiver penderita gangguan skizofrenia. Jurnal Empati, 3(4), 1-13.

Vasilopoulou, E., \& Nisbet, J. (2016). The quality of life of parents of children with autism spectrum disorder: A systematic review. Research in Autism Spectrum Disorders, 23, 36-49. https://doi. org/10.1016/j.rasd.2015.11.008

Voci, A., Veneziani, C. A., \& Fuochi, G. (2018). Relating mindfulness, heartfulness, and psychological well-being: The role of selfcompassion and gratitude. Mindfulness, 10(2), 339-351. https://doi.org/10.1007/ s12671-018-0978-0

Wasserman, S., De Mamani, A. W., \& Suro, G. (2012). Shame and guilt/self-blame as predictors of expressed emotion in family members of patients with schizophrenia. Psychiatry Research, 196(1), 27-31. https://doi.org/10.1016/j. psychres.2011.08.009

Wood, A. M., Froh, J. J., \& Geraghty, W. A. (2010). Gratitude and well-being: A review and theoretical integration. Clinical Psychology Review, 30(7), 890-905. Retrieved from doi: 10.1016/j. cpr.2010.03.005

Wood, A. M., Joseph, S., \& Linley, P. A. (2007). Coping style as a psychological resource of grateful people. Journal of Social and Clinical Psychology, 26(9), 1076-1093. https://doi.org/10.1521/jscp. 2007.26.9.1076

Wood, A. M., Joseph, S., \& Maltby, J. (2009). Gratitude predicts psychological well-being above the big five facets. Personality and Individual Differences., 46, 443-447.

Zhang, Y., Subramaniam, M., Lee, S. P., Abdin, E., Sagayadevan, V., Jeyagurunathan, A., ... Chong, S. A. (2018). Affiliate stigma and its association with quality of life among caregivers of relatives with mental illness in Singapore. Psychiatry Research, 265, 55-61. https://doi. org/10.1016/j.psychres.2018.04.044 